\title{
PRÁTICAS EM EDUCAÇÃO AMBIENTAL NO ENSINO MÉDIO: O USO E DESTILAÇÃO DE FERMENTADO DE CALDO DE CANA DE AÇÚCAR COMO FERRAMENTA DIDÁTICA PARA A EDUCAÇÃO BÁSICA
}

\author{
Rayani Garcia ${ }^{1}$ \\ Valéria Carvalho ${ }^{2}$ \\ Washington Carneiro ${ }^{3}$
}

Resumo: $O$ presente artigo tem como objetivo apresentar uma sequência didática para descrever o processo de produção do álcool a partir da fermentação e destilação do mosto de cana de açúcar e desenvolver conceitos químicos, biológicos, históricos e sociais no decorrer da sua aplicação. O experimento prático desenvolvido no artigo resultou como ferramenta didática relevante para exposição dos processos físico-químicos, biológicos e sociais, permitiu também abordar os danos ao meio ambiente e promoveu de forma integrada a Educação Ambiental em alunos do segundo ano do ensino médio ao propor um debate sobre o experimento voltado para a formação de uma consciência ecológica.

Palavras-chave: Educação Ambiental; Destilação Alcoólica; Sequência Didática.

${ }^{1}$ Instituto Federal Do Espírito Santo. E-mail: rayanigarciasilva@gmail.com

${ }^{2}$ Instituto Federal Do Espírito Santo. E-mail: valeriabcarvalho1@gmail.com

${ }^{3}$ Instituto Federal Do Espírito Santo. E-mail: wpscarneiro@hotmail.com

ambiental

Revbea, São Paulo, V. 14, № 2: 268-276, 2019. 


\section{Introdução}

A ideia construtivista de ensino abrange uma variedade de aulas, principalmente aquelas que envolvem 0 aluno diretamente com 0 conhecimento, onde se valorizam os saberes prévios e se coloca o aluno frente a frente com os objetos em estudo.

A partir do experimento prático, multidisciplinar, simples e de baixo custo, este artigo tem como objetivo geral contribuir para a sensibilização de alunos do ensino médio em relação à proteção do meio ambiente através da fermentação do mosto de cana de açúcar, a destilação para a obtenção de álcool e seus impactos na natureza.

Realizado em sala de aula, por estudantes do ensino médio, o experimento e todo processo de obtenção do álcool, por meio de uma sequência didática, buscou promover a consciência ambiental através da identificação e exposição dos impactos causados pelos processos industriais da produção de álcool.

Essa experiência, procurou despertar nos alunos do ensino médio, a percepção da necessidade de preservação do meio ambiente através de medidas que mitiguem os impactos causados por esse processo, que é realizado atualmente em grande escala industrial para 0 atendimento de demandas do mercado consumidor. Dessa forma, pretendeu também levá-los à reflexão quanto à participação cidadã no que se refere à Educação Ambiental, a fim de promover ideais de sustentabilidade.

A fim de alcançar tais objetivos, propõe-se, por exemplo, a inserção de tecnologias nas salas de aulas em prol da difusão do conhecimento, formação contínua dos professores, mudança radical nos planejamentos das aulas, envolvimento dos pais e comunidade dentro dos projetos da escola. Enfim, uma série de medidas para que, de fato, o aluno seja estimulado a pensar por si próprio e a ser produto de novos conhecimentos. É nesse contexto que se inserem as aulas práticas.

Um método capaz de aproximar ainda mais os alunos do objeto estudado, segundo Hodson (1994, p. 301) aula prática se caracteriza como qualquer atividade em que os alunos estejam ativos e não passivos; e ainda, reconhece esta modalidade como meio eficiente para melhorar o aprendizado e fortalecer explicações teóricas. Para Andrade e Massabni (2011, p. 840), aulas práticas são: aquelas tarefas educativas que requerem do estudante a experiência direta com o material presente fisicamente, com o fenômeno e/ou com dados brutos obtidos do mundo natural ou social.

Ademais, a atividade prática é a interação entre o aluno e materiais concretos, por meio desse envolvimento, que se torna natural e social, estabelecem-se relações que irão abrir possibilidades de atingir novos conhecimentos (VASCONCELLOS, 1995).

Sabendo que o objetivo do professor é que seu aluno adquira conhecimento e aprenda os conteúdos trabalhados, muitas vezes, só é

revista brasileira educação ambiental 
possível atingir a compressão de determinados conteúdos com o trabalho de aulas práticas (FROTA-PESSOA; GEVERTZ; SILVA, 1985). As aulas práticas trazem inúmeros benefícios para compreensão do aluno.

Segundo Ribas e Uhmann (2016, p.7), que abordam experiência no ensino de Ciências:

A experimentação no ensino de Ciências provoca questionamentos aos estudantes, no qual alguns conceitos não serão aceitos facilmente, mas se adequaram a explicação da prática proposta, causando a necessidade de busca/pesquisa dos conhecimentos científicos por parte dos alunos e do professor, se necessário, pois através da ação da pesquisa buscam o que procuram. Essa ação pode ser contínua e circular, uma vez que o professor viabilize vários questionamentos e/ou reflexões, discussões, sobre 0 experimento que for proposto.

Quando o aluno faz uma pesquisa, aprende a formular hipóteses, a experimentar, a observar, a trabalhar em grupo e a tirar conclusões, consequentemente, ele começa a aprender conceitos científicos, relações entre o meio e o ser vivo, a ser mais paciente, responsável e tolerante, denotando assim maior aptidão para o aprendizado (PILETTI, 1988).

\section{Trabalhos relacionados}

Os seguintes trabalhos foram selecionados pela relevância para o direcionamento do presente artigo: uma sequência didática sobre destilação da cachaça: da contextualização histórica ao compromisso social de Celante, Terra e Celante (2016), Didáticas e formação de professores: provocações de Gatti (2017) e Mini Projetos para ensino geral experimental baseado na fermentação do caldo-de-cana, de Peixoto et al. (2012).

Celante, Terra e Celante (2016) propõem através de um estudo de caso uma sequência didática sobre a "destilação da cachaça" aplicada ao ensino básico. A sequência didática teve como proposta partir da contextualização sugerida no currículo básico comum (CBC) e concluir com o desenvolvimento dos alunos. Em um compromisso social, os principais conceitos abordados são: alfabetização científica, história da ciência e a história da química no Brasil. O artigo apresenta em sua conclusão que o trabalho traz pontos fortes para o processo do ensino de ciências, porém, ainda apresenta alguns pontos e lacunas que deverão ser mais bem trabalhados.

Em relação a didática e formação de professores, Gatti (2017) discorre sobre o levantamento dos principais questionamentos que a respeito da formação de professores e reflete sobre as demandas das escolas na contemporaneidade. $\mathrm{O}$ autor aborda documentos oficiais, a partir do ano de

Revbea, São Paulo, V. 14, № 2: 268-276, 2019. 
2015 que foram escritos para orientar a formação de docentes para a educação básica. Tais documentos levaram em consideração o novo plano nacional de educação e os documentos do conselho nacional de educação e explora através desses documentos o conhecimento do campo da didática.

Para o direcionamento experimental, foi de significativa contribuição o artigo de Peixoto et al. (2012), pois descreve um miniprojeto de cinco semanas para um curso de laboratório de química geral incluindo as atividades de preparo de soluções de etanol e sacarose, cálculo de concentração, fermentação de cana e a determinação de quantidades de etanol e CO2 formadas.

\section{Metodologia}

A pesquisa desenvolvida em nossa proposta de estudo teve abordagem qualitativa e participante. Quanto aos objetivos, teve caráter descritivo e exploratório. A execução deste trabalho foi realizada em um espaço formal de educação com alunos da educação básica.

Para a realização do trabalho, inicialmente foi feita uma revisão bibliográfica para investigar o que foi produzido acerca das aulas de história, química e meio ambiente e sua ineficiência para a propagação do conhecimento. Em seguida, seguida definimos a sequência didática para melhorar o ensino e especificamente o ensino de ciências, química e história, e relacionamos com Educação Ambiental.

\section{Sequência didática}

A sequência didática transcorreu ao longo de quatro aulas de 50 minutos lecionadas para o $2^{\circ}$ ano do ensino médio. Ao longo das aulas, os alunos desenvolveram competências e habilidades fundamentais de forma interdisciplinar. Além disso, conheceram um pouco mais sobre os processos de produção do álcool, a partir do processo de destilação simples com referências à história e o desenvolvimento dos processos de fermentação ao longo da evolução do conhecimento humano.

De forma específica, os alunos foram sensibilizados com relação a proteção do meio ambiente através de exemplos práticos, como o dos impactos na natureza a partir dos processos industriais, correlacionaram conceitos químicos, biológicos e históricos com a produção do álcool.

Ao final da sequência didática, constatamos a conscientização ambiental por meio dos debates sobre o processo de produção e seus impactos na natureza. Além disso, desenvolveram a percepção da necessidade de preservação do meio ambiente através da exposição de medidas que mitiguem os impactos causados por esse processo. Coletivamente concluíram sobre a necessidade da participação dos sujeitos sociais como cidadãos no que se refere à promoção de uma Educação Ambiental, bem como por meio do 
diálogo com o Programa Nacional de Educação Ambiental promoveram ideais de sustentabilidade.

Identificaram danos e apontaram algumas ações que contribuem para uma produção sustentável, além da formação de uma consciência ambiental voltada para cidadania por meio da perspectiva da Educação Ambiental que oriente no sentido da preservação do meio ambiente.

A sequência de passos da ação educativa obedeceu às seguintes etapas e sua correspondente descrição:

\section{$\underline{\text { AULA } 1}$}

Abordagem comunicativa: (20 minutos): as aulas se iniciaram com uma apresentação do processo de fermentação e sua presença na história da humanidade passando pela antiguidade, da Europa medieval até os processos de produção industrial, após a segunda fase da Revolução Industrial no século XIX. A abordagem do processo de fermentação produção do álcool ao longo da história da humanidade (Sumérios, egípcios, indígenas americanos, Europa medieval - A virada metodológica com a industrialização e os processos de produção em escala industrial) com destaque para a ampliação da poluição e a necessidade de preservação do meio ambiente onde foi abordada a relação entre história e ambiente com ênfase na necessidade do contato do homem com a natureza e a importância da preservação do meio ambiente.

Material de apoio: Apresentação de slides e panorama histórico e social dos processos de fermentação

Abordagem interativa e dialógica (20 minutos): problematização do que se entende por alcoolismo, patologias causadas pelo álcool. Produção de álcool e seus impactos sobre o meio ambiente.

Conclusão (10 minutos): finalização com slides, apresentação dos conceitos a serem trabalhados na sequência e sugestão para preparação do mosto de caldo de cana de açúcar com fermento, bicarbonato e açúcar que será reservado em garrafa PET por uma semana sem isolamento.

\section{AULA 2}

Etapas do processo produtivo (25 minutos): Apresentação das fases do processo de produção de álcool a partir de vídeo curto e apresentação de conceitos químicos e biológicos. Foi discutido e apresentado:

A moagem e a relação entre os detritos e seus impactos, bem como a apresentação da relação entre as propriedades da matéria e os cálculos envolvidos. Destacando a presença dos micro-organismos envolvidos, as equações químicas e a reação de fermentação que produz o álcool.

Os materiais e equipamentos necessário, como a torre de destilação simples e fracionada. Apresentação das forças intermoleculares presentes no Revbea, São Paulo, V. 14, № 2: 268-276, 2019. 
processo, o ponto de ebulição, a diferença entre a destilação simples e fracionada.

Material de apoio Slides e vídeo disponível no YouTube sobre a produção de álcool.

\section{$\underline{\text { AULA } 3}$}

Abordagem interativa e dialógica (10 minutos): Introdução expositiva com a retomada dos conceitos e proposição de atividades conceituais a partir de questionário.

Abordagem interativa e dialógica 10 minutos): Introdução expositiva com a retomada dos conceitos e proposição de atividades conceituais a partir de questionário.

Atividade proposta (30 minutos): Identificação dos agentes biológicos presentes no processo de fermentação do mosto de caldo de cana de açúcar. Balanceamento de equação da reação de produção do álcool.

Material de apoio: Questionário elaborado e adaptado de forma interdisciplinar para exploração dos conhecimentos apresentados nas aulas anteriores envolvendo o processo de produção do álcool, os agentes biológicos e os conceitos químicos presentes no vídeo.

Conclusão (10 minutos): Resolução da atividade proposta.

\section{AULA 4}

Abordagem interativa e dialógica (10 minutos): Exposição dos materiais necessários para destilação simples e retomada dos conceitos que serão apresentados no exemplo prático a partir dos processos de produção de álcool por meio de destilação simples.

Montagem e organização do material (10 minutos): Explicação do funcionamento das partes do material a ser utilizado no processo de destilação.

Exemplo prático (30 minutos): Destilação de meio litro de mosto de caldo de cana de açúcar a $80^{\circ}$ graus para extração de álcool que esteve em repouso por uma semana.

Material de apoio: Termômetro, rolha, balão de destilação, condensador, Erlenmeyer, bico de Bunsen, suporte universal e tripé. Meio litro de caldo de cana de açúcar. Um tablete de 15 gramas de fermento biológico. Meia colher de sobremesa de bicarbonato de sódio. Três colheres de açúcar. O mosto a ser destilado foi reservado durante uma semana. 


\section{Resultados}

A partir do relato de experiência abaixo, foi possível adequar ações para as disciplinas onde a experiência pode ser aplicada. Sendo assim o mesmo é um recurso relevante junto à sequência de didática, orientando o processo, evitando assim erros, que pudessem atrapalhar o andamento da sequência didática, assim como do aprendizado dos alunos.

\section{Relato da experiência: Relatório de análise de destilação a partir de fermentado de cana de açúcar:}

O experimento em questão teve como objetivo produzir etanol a partir do caldo de cana através de fermentação alcoólica.

Levando em conta aspectos teóricos e práticos do assunto, o experimento foi desenvolvido como meio para aplicar a transdisciplinaridade na educação. O estudo durou cinco dias, no mês de setembro de 2018, onde três amostras diferentes foram destiladas, mediante observações, relatos orais e escritos em diários de bordo e fotografias, assim como revisão bibliográfica e orientações técnicas do responsável do laboratório de química, onde ocorreu a destilação.

Para a realização da atividade, três amostras de $500 \mathrm{ml}$ de caldo de cana de açúcar fresco foram recolhidas para destilação e análise dos resultados obtidos a partir da destilação simples. Todas elas foram colocadas, cada uma, em um recipiente plástico de Polietileno Tereftalato (PET) sem tampa para auxiliar na fermentação de tipo aeróbica. Dois transparentes e o terceiro recipiente da amostra 3, de coloração escura esverdeada (Figura 1).

Em cada uma das amostras foi colocado um tablete de fermento biológico de cerca de 15 gramas para o processo de fermentação.

$\mathrm{Na}$ amostra 1: Em recipiente transparente, além do fermento biológico, foram adicionadas duas colheres de açúcar e meia colher de chá rasa de bicarbonato de sódio. Foram destilados exatamente $500 \mathrm{ml}$ de amostra .

A amostra em questão apresentava coloração mais escura e um forte odor, característico da fermentação. A destilação desta amostra começou às 9h30min da manhã, com duração de 40 minutos, uma vez que o experimento se encerrava quando o termômetro atingia valor superior a $80^{\circ} \mathrm{c}$. Obtivemos como resultado dessa amostra $30 \mathrm{ml}$ de etanol ou álcool.

$\mathrm{Na}$ amostra 2, em recipiente transparente, o fermento biológico e duas colheres de açúcar.

$\mathrm{Na}$ amostra 3, em recipiente de coloração escura, apenas o fermento biológico.

No primeiro dia, a amostra apresentou coloração escurecida e o cheiro característico produzido pela fermentação começou a aparecer. Os recipientes foram sacudidos e deixados para descansar. 
No segundo dia, o cheiro da fermentação já estava bem mais definido. Também foi realizado o mesmo procedimento. Os recipientes foram sacudidos para que a mistura se tornasse homogênea e depois, deixadas descansar novamente.

No terceiro dia, as amostras já apresentavam alguma alteração significativa no cheiro e na coloração mais escurecida resultante do processo de fermentação.

No quarto dia, foram separadas e levadas para a destilação no laboratório de química do Instituto Federal do Espírito Santo para análise dos resultados após quatro dias de fermentação.

No laboratório, os materiais de vidraria foram utilizados para destilação simples. O principal método de produção do álcool é por meio da fermentação do melaço da cana-de-açúcar. Essa fermentação é realizada por microorganismos, principalmente leveduras da espécie Saccharomyces cerevisae, que, na presença da sacarose (açúcar), elaboram uma enzima chamada de invertase que atua como catalisadora da reação de hidrólise da sacarose, transformando-a em glicose e frutose. Depois, o micro-organismo elabora outra enzima, a zimase, que catalisa a transformação da glicose e da frutose em etanol, além de liberar também gás carbônico, que dá o aspecto da fermentação cheio de bolhas.

\section{Conclusões}

Este trabalho apresentou uma proposta de sequência didática com o desenvolvimento de conceitos químicos, biológicos, históricos e sociais ao longo da sua aplicação. O experimento prático e os resultados permitiram abordar os danos que a produção industrial em grande escala pode acarretar ao meio ambiente e a conscientização da necessidade de preservação ambiental. Através de debates e conversas, os alunos buscaram alternativas sustentáveis para minimizar os danos ambientais causados pelo processo de produção industrial de álcool.

Desse modo, ao final do processo os alunos tinham tido ferramentas capazes de aprimorar seu conhecimento, acerca do conteúdo de química, história e ciência e outras disciplinas que são possíveis de relacionar a Educação Ambiental. Em relação a sequência aqui proposta os alunos devem conseguir compreender a relação dos processos históricos relacionados à produção de álcool; as reações químicas envolvidas; a relação de seres vivos com a fermentação. Além de promover uma consciência ambiental relacionada ao assunto.

Educar é uma atividade que necessita de tempo, mesmo assim, é estimulante. $\mathrm{Na}$ qual requer inovação e experimentações. Por isso o presente trabalho pode servir de apoio para novas pesquisas relacionadas a esse assunto. 


\section{Referências}

ALVES, F.C. Diário: contributo para o desenvolvimento profissional dos professores e estudo dos seus dilemas. Millenium: Revista do ISPV, [S.I.], n. 29, p. 222-239, dez. 2004.

ANDRADE, M.L.F; MASSABNI, V.G. O desenvolvimento de atividades práticas na escola: Um desafio para professores de Ciências. Ciência \& Educação, v.17, n.4, p. 835-854, 2011. Disponível em:

CELANTE, G.X.M.; TERRA, V.R.; SGARBI, A.D.; CELANTE, V.G. Uma sequência didática sobre destilação da cachaça: da contextualização histórica ao compromisso social. XVIII Encontro Nacional de Ensino de Química, Florianópolis, SC, 2016. Disponível em: <.http://www.eneq2016.ufsc.br/anais /resumos/R1510-1.pdf>. Acesso em: $11 \mathrm{dez} .2018$.

Como a cana de açúcar vira etanol? Etanol sem fronteira - episódio 3. Petrobras. Disponível em: <https://www.youtube.com/watch?v=zFfpQsne bg>. Acesso em: 05 Nov. 2018.

FROTA-PESSOA, O.; GEVERTZ, R.; SILVA, A.G. Como ensinar ciências. 5.ed. São Paulo: Nacional, 1985.

GATTI, B.A. Didática e formação de professores: Provocações. Caderno de Pesquisa da Fundação Carlos Chagas, São Paulo, SP, v. 47, n. 166, p. 1150-1164, 2017.

HODSON, D. Hacia um enfoque más crítico del trabajo de laboratório. Enseñanza de las Ciencias, v.12, n. 13, p.299-313, 1994.

OLIVEIRA, A.M; STROSCHOEN, A.G. Diário de bordo: Uma ferramenta para o registro da alfabetização científica. Tese (Mestrado) - Programa de Pósgraduação em ensino de ciências exatas, Centro Universitário UNIVANTES. Disponível em: < https://www.univates.br/ppgece/media/pdf/2015/aldeni melo de oliveira.pdf>. Acesso em: 07 Dez. 2018.

PEIXOTO, C.R.M.; ROSA, G.R.; SILVA, C.N.; SANTOS, B.T.; ENGELMANN, T.L. Miniprojeto para ensino de Química Geral Experimental baseado na fermentação do caldo de cana-de-açúcar. Revista Química Nova, São Paulo, SP, v. 35, n. 8, p. 1686-1691, 2012.

PILETTI, C. (Org.) Didática especial. 6.ed. São Paulo: Ática S.A, 1988.

PORLÁN, R.; MARTíN, J. El diario del profesor. Enseñanza de las ciencias: Revista de investigación y experiencias didáctica. Sevilla: Díada Ed., 1997.

RIBAS, C.P.; UHMANN, R.I.M. Aulas práticas/teóricas em ciências: uma memória reflexiva na formação docente. Revista da SBEnBio - Número 9. 2016.

VASCONCELLOS, C.D.S. Planejamento: plano de ensino: aprendizagem e projeto educativo. 4.ed. São Paulo: Libertad, 1995. 